\title{
Menulis Artikel untuk Publikasi di Jurnal Bereputasi
}

\author{
Ismail Suardi Wekke \\ Sekolah Tinggi Agama Islam Negeri (STAIN) Sorong, Indonesia \\ College University of Yayasan Pahang, Malaysia \\ Email: iswekke@gmail.com \\ Workshop Penelitian Tingkat Unggul \\ Institut Agama Islam Negeri (IAIN) Bukittinggi \\ Padang, 22-24 November, 2019
}

\begin{abstract}
ABSTRAK
Artikel ini mendeskripsikan lima perkara terkait dengan menulis artikel jurnal. terutama untuk jurnal bereputasi. Semuanya terkait dengan proses penulisan artikel secara teknis. Rambu-rambu yang tertulis dalam penulisan artikel sepenuhnya perlu merujuk kepada pedoman penulisan yang disiapkan oleh editor jurnal. Satu hal lagi, referensi yang digunakan perlu mengemukakan rujukan utama. Dimana baik state of the art maupun diskusi perlu menunjukkan milestone apa yang telah dipublikasikan oleh ilmuwan dalam topik terkait.
\end{abstract}

Kata Kunci: artikel; struktur penulisan; kriteria.

\section{Pendahuluan}

Artikel ini merupakan catatan-catatan ringkas dalam proses pelaksanaan workshop dan juga semasa membaca artikel yang ditulis oleh para peserta workshop. Untuk itu, artikel mengemukakan bagian-bagian yang tidak komprehensif dan hanya mengidentifikasi kaitan dengan artikel yang menjadi bagian dari proses diskusi selama workshop berlangsung.

Untuk itu, dapat membaca artikel antara lain (Wekke \& Farid, 2019), menyintesis literatur (Rahayu, Syafril, \& Wekke, 2019), menulis literatur (Rahayu, Syafril, Wekke, \& Erlinda, 2019), menulis artikel jurnal (Wekke, 2019a), memperkaya referensi (Wekke, 2019). Termasuk penggunaan tekonologi informasi (Nur, Sabara, \& Wekke, 2018), menulis di Scopus (Wekke, 2015).

\section{Apa Obyek yang Ditulis?}

Diperlukan data yang dapat diverifikasi. Bahkan menulis tentang Alquran dapat dijadikan sebagai artikel jurnal (Yusuf, Nahdhiyah, \& Wekke, 2019). Tidak harus dalam bentuk "lapangan" realitas. Dapat pula sebuah buku, naskah, ataupun manuskrip. Silahkan lihat karya Fathurahman, seperti artikel tentang kitab hadis (Fathurahman, 2012), wahdat al-wujud (Fathurahman, 2011).

Begitu pula pandangan masyarakat tentang sebuah tema (Yusuf, Wekke, \& Yudha, 2018). Atau bahkan penelitian tindakan kelas (Yusuf, \& Wekke, 2015; Wekke, 2015). 
Ada data yang dikaji. Sehingga dapat diverifikasi oleh pembaca. Bukan sekadar argumentasi tetapi tidak ada obyek kajian. Walaupun mengkaji filsafat tetapi ada obyek yang dapat digunakan sebagai data riset, seperti kajian Al-Ghazali (Muhammad Amin Abdullah, 1992; Abdullah, 2017a; Abdullah, 2017b)

\section{Karakteristik Artikel jurnal}

Pertama penggunaan kalimat. Space yang sangat terbatas, maka artikel harus ditulis dengan ajeg. Perlu dibedakan dengan budaya bertutur yaitu dengan tidak menggunakan kutipan langsung. Begitu pula menghindari penuturan seperti:

"Pakar A menyatakan dalam buku yang berjudul"

Ini dapat diperbaiki dengan menulis menjadi

"sebagaimana dinyatakan A bahwa ..."

Kedua, jangan biarkan dalam satu rujukan hanya menarasikan pendapat orang lain. Perlu dikemukakan apa pendapat penulis.

Ketiga, bagian awal perlu mengemukakan "state of the art". Bagian ini menyatakan apa saja existing artikel yang terpublikasi. (Lucas, 2012; Messenheimer, \& Packwood, 2002; QuillerCouch, 1916).

State of the art dapat diartikan sebagai pengembangan mutakhir sebuah diskursus keilmuan. Sehingga apa yang sudah ada sesuangguhnya menjawab persoalan yang sudah ada kemaren. Penulisan artikel hari ini menjawab pertanyaan hari ini. Bisajadi, persoalan hari ini sudah terjadi juga sebelumnya, sehingga rujukan dari masa lalu dapat saja digunakan saat sekarang.

Keempat, novelty. Tak harus benar-benar baru. Bisajadi sebuah modifikasi seperti dalam artikel tentang pembelajaran bahasa Arab di Sorong (Wekke, \& Andriansyah, 2016).

Kelima, di bagian pendahuluan perlu ada tujuan penulisan. Bisa dituliskan dalam bentuk pertanyaan atau bisa pula dalam bentuk pernyataan. Penulis perlu menggunakan kalimat operasional dengan berpatokan pada taksonomi Bloom (1956).

Keenam, wawasan artikel. Sebuah fenomena bisa saja lokal. Tetapi sebagai bagian dari aspek kehidupan, maka ini bisa juga wujud di tempat lain dalam bentuk yang berbeda.

\section{Penggunaan Referensi:}

Paling tidak dalam dua bagian yaitu pendahuluan dan diskusi. Perlu ada referensi dengan kriteria 1) primer, 2) mutakhir, dan 3) dapat ditemukan online. 
Referensi primer antara lain: artikel jurnal, skripsi, tesis, disertasi, laporan penelitian. Hindari menggunakan Wikipedia, blogspot, wordpres, ataupun Kompasiana dan media sosial lainnya. Itu adalah bentuk-bentuk jurnalisme warga.

Kecuali sebagai obyek atau data penelitian, itu dapat saja diteliti. Namun sebagai referensi tidak dapat digunakan sama sekali.

Silahkan lihat detail "Memulai dari Akhir" (Wekke, 2019b) dalam tautan sebagai berikut: https://www.youtube.com/watch?v=KUTYVgrmO6g\&t=2s.

Sebuah data berbeda dengan referensi. Untuk penggunaan data, sebagaimana dalam ilmu sejarah, semakin tua semakin bagus. Sementara untuk referensi semakin mutakhir semakin bagus. Data dimasukkan dalam bagian result sementara referensi digunakan untuk menulis state of the art dan diskusi.

Selanjutnya, hindari menggunakan rujukan sekunder sebagaimana dalam contoh kalimat:

“Menurut Muchtar Nai’m yang dikutip Basyral Hamidy Harahap ...”

Ini berarti tidak membaca Muchtar Na'im tetapi membaca Basyral Hamidy Harahap. Gaya penulisan dengan rujukan seperti ini, tidak perlu digunakan dalam penulisan artikel jurnal.

Satu hal lagi, referensi utama. Jika mengkaji tentang Minangkabau, maka ada penelitianpenelitian awal yang ditulis tentang Minangkabau. Itu perlu dirujuk baik dalam pendahuluan maupun diskusi.

Contoh lainnya adalah penelitian tentang pesantren. Maka, penelitian Dhofier (1982), Mastuhu (1984), Mas'ud (2004), Lukens-Bull (2001), tidak dapat ditinggalkan. Ini adalah penelitianpenelitian tentang pesantren. Dua penelitian yang disebutkan, merupakan penelitian awal pesantren yang terpublikasi.

Maka, muncullah pertanyaan "bagaimana pesantren di minoritas muslim?. Maka, dapat ditemukan jawaban tentang itu dalam artikel tentang keberagamaan mahasiswa (Wekke, Hermawanto, \& Ashrori, 2016), kurikulum madrasah (Wekke, \& Astuti, 2017), lembaga pendidikan di Manado (Wekke, 2013), pendidikan bahasa Arab di Bali (Wekke, 2018).

\section{Apa ide yang menarik?}

Sebelum itu, seorang penulis paling tahu apa yang menjadi current issues dalam bidang ilmunya masing-masing.

Sebagai contoh: kalau menulis tentang Islam dan Adat, maka silahkan lihat Taufik Abdullah (1966) terkait dengan identitas (Abdullah, 1978), Tradisi (Abdullah, 1989), Kaba Tjindua Mato (Abdullah, 1970), Kaum Muda (Abdullah, 2009). 
Maka, membaca secara lengkap karya-karya Taufik Abdullah akan membantu dalam menulis tentang Minangkabau. Tetapi bukan itu saja.

Sprektrum tentang Minangkabau beragam dalam tema-tema perang Padri (Wahyuni, 1988), angkutan kota (Alamanda, 2010), parkir (Zayu \& Fitri, 2019), berburu babi (Arifin, 2012), perempuan (Blackwood, 2001).

Ini sekadar contoh saja, pelbagai artikel yang berkaitan dengan Minangkabau tersenarai dalam bibliografi tersendiri sehingga perlu dibaca secara komprehensif.

Ada pandangan bahwa Islam dan Minangkabau bagai sisi mata uang yang saling melengkapi. Pertanyaanya "apakah semua warga Minangkabau muslim?. Jawaban dapat ditemukan melalui penelitian Ilahi dan Rabain (2019), Ilahi (2018), Anggraini (2015), Sinaga (2018), Desi (2011).

\section{Aspek Bahasa}

Dalam sebuah paragraf terdiri atas beberapa kalimat, bukan hanya satu kalimat. Silahkan dirujuk (Paul, \& Elder, 2019).

Sementara paragraf merupakan bagian dari komposisi. Lihat kembali (Keraf, 1980).

Antara satu paragraf dengan paragraf lainnya perlu kohesi dan coherence.

\section{Penutup}

Penulisan artikel tidak dapat dilakukan sekali jadi. Begitu pula soal durasi waktu penerbitan yang juga tidak seperti dengan Koran yang terbitnya harian, atau tabloid yang terbit setiap pekan. Namun jurnal paling tidak terbit dalam ukuran bulan.

Untuk itu, mempersiapkannya juga memerlukan waktu dan sekaligus memeriksa kembali terkait dengan aspek terkecil sekalipun. Ini berkaitan dengan editor, mitra bestari, dan juga penyuntingan.

\section{Daftar Pustaka}

Abdullah, M. A. (2017a). Islamic Studies in Higher Education in Indonesia: Challenges, Impact and Prospects for the World Community. Al-Jami'ah: Journal of Islamic Studies, 55(2), 391-426.

Abdullah, M. A. (2017b). Islam as a Cultural Capital in Indonesia and The Malay World: A Convergence of Islamic Studies, Social Sciences and Humanities. Journal Of Indonesian Islam, 11(2), 307-328.

Abdullah, M. E. (1992). The Idea of Universality of Ethical Norms in Ghazali and Immanuel Kant. Türkiye diyanet vakfi.

Abdullah, T. (1966). Adat and Islam: An examination of conflict in Minangkabau.

Abdullah, T. (1970). Some notes on the Kaba Tjindua Mato: An example of Minangkabau traditional literature. Indonesia, (9), 1-22. 
Abdullah, T. (1978). Identity Maintenance and Identity Crisis in Minangkabau. Identity and Religion: International, Cross-Cultural Approaches. Beverly Hills, CA: Sage (151-167).

Abdullah, T. (1989). II. Islam and the Formation of Tradition in Indonesia: A Comparative Perspective. Itinerario, 13(1), 17-36.

Abdullah, T. (2009). Schools and Politics: The Kaum Muda Movement in West Sumatra (19271933). Equinox Publishing.

Alamanda, Z. (2010). Graffiti Berbahasa Minangkabau Pada Angkutan Kota Di Kota Padang. Wacana Etnik, 1(2), 129-140.

Anggraini, N. (2015). Pergeseran Nilai Budaya Minangkabau Dalam Novel Dari Surau Ke Gereja Karya Helmidjas Hendra Dan Novel Persiden Karya Wisran Hadi (Tinjauan Sastra Banding). Jurnal Dinamika UMT, 1(1), 63-70.

Arifin, Z. (2012). Buru Babi: Politik Identitas Laki-Laki Minangkabau. Jurnal Humaniora, 24(1), 29-36.

Blackwood, E. (2001). Representing women: the politics of Minangkabau Adat writings. The Journal of Asian Studies, 60(1), 125-149.

Bloom, B. S. (1956). Taxonomy of educational objectives. Vol. 1: Cognitive domain. New York: McKay, 20-24.

Desi, N. (2011). Sejarah Perkembangan Gereja Gpib Efrata Padang 1948-2009 (Doctoral dissertation, Universitas Andalas).

Dhofier, Z. (1982). Tradisi pesantren: Studi tentang pandangan hidup kyai. Lembaga Penelitian, Pendidikan, dan Penerangan Ekonomi dan Sosial.

Farid, M., \& Wekke, I. S. (2019, August 7). Proses Menulis Artikel Ilmiah: Dari Ide Hingga

Publikasi. https://doi.org/10.31227/osf.io/yhpvm

Fathurahman, O. (2011). Ithāaf al-dhakī by Ibrāhīm al-Kūrānī: A Commentary of Waḥdat alWujūd for Jāwī Audiences. Archipel, 81(1), 177-198.

Fathurahman, O. (2012). The roots of the writing tradition of hadīth works in Nusantara: Hidāyāt Al-Habīb by Nūr Al-Dīn Al-Rānīrī. Studia Islamika, 19(1).

Ilahi, K. (2018). Konversi Agama pada Masyarakat Minangkabau. Religió: Jurnal Studi Agamaagama, 8(2), 164-185.

Ilahi, K., \& Rabain, J. (2019). Dari Islam ke Kristen Konversi Agama pada Masyarakat Suku Minangkabau. Madania: Jurnal Ilmu-Ilmu Keislaman, 8(2), 201-227.

Kellogg, R. T. (2006). Professional writing expertise. The Cambridge handbook of expertise and expert performance, 389-402.

Keraf, G. (1980). Komposisi. Nusa Indah.

Lucas, F. L. (2012). Style: The Art of Writing Well. Harriman House Limited.

Lukens-Bull, R. A. (2001). Two sides of the same coin: Modernity and tradition in Islamic education in Indonesia. Anthropology \& education quarterly, 32(3), 350-372.

Mas' ud, A. (2004). Intelektual Pesantren: Perhelatan Agama dan Tradisi. Jawa Pos Press.

Mastuhu. (1994). Dinamika sistem pendidikan pesantren: suatu kajian tentang unsur dan nilai sistem pendidikan pesantren. INIS.

Messenheimer, T., \& Packwood, A. (2002). Writing: the state of the state vs. the state of the art in English and American schools. Reading, 36(1), 11-15.

Nur, T., Sabara, H. Z., \& Wekke, I. S. (2018). Teknik Menulis Karya Ilmiah: Dengan 8 Senjata Aplikasi Pendukung Produktivitas Riset. Deepublish.

Paul, R., \& Elder, L. (2019). How to write a paragraph: The art of substantive writing. Rowman \& Littlefield.

Quiller-Couch, A. T. (1916). On the art of writing: Lectures delivered in the University of Cambridge, 1913-1914. University Press.

Rahayu, T., Syafril, S., \& Wekke, I. S. (2019). Menyintesis Literatur Dalam Penulisan Artikel.

https://doi.org/10.31227/osf.io/fxnha. 
Rahayu, T., Syafril, S., Wekke, I. S., \& Erlinda, R. (2019, September 15). Teknik Menulis Review Literatur Dalam Sebuah Artikel Ilmiah. https://doi.org/10.31227/osf.io/z6m2y.

Sinaga, Y. M. (2018). Gerakan Mahasiswa Kristen Indonesia (GMKI) Cabang Padang dalam Gerakan Mahasiswa Tahun 1990-1998 di Kota Padang (Doctoral dissertation, Universitas Negeri Padang).

Wahyuni, S. (1988). Peranan agama dalam perang Padri (tahun 1821-1837) (Doctoral dissertation, IAIN Sunan Ampel Surabaya).

Wekke, I. S. (2013). Lembaga Pendidikan Sebagai Pilar Dakwah di Wilayah Minoritas Muslim. Jurnal Dakwah Alhikmah, 4(2), 93-118.

Wekke, I. S. (2015). Arabic teaching and learning: A model from Indonesian muslim minority. Procedia-Social and Behavioral Sciences, 191, 286-290.

Wekke, I. S. (2015). Teknik penulisan artikel untuk jurnal dengan indeks Scopus. Workshop on Management and Writing for International Journal Hasanuddin Law Review, Makassar 1-2 November 2015

Wekke, I. S. (2018). Pembelajaran Bahasa Arab di Pesantren Minoritas Muslim Bali. SOSIOHUMANIKA, 11(1), 79-96.

Wekke, I. S. (2019a). Menulis Artikel Jurnal. https://doi.org/10.31227/osf.io/p4s3c.

Wekke, I. S. (2019b). Memulai dari Akhir. Zenodo. http://doi.org/10.5281/zenodo.3551889.

Wekke, I. S., \& Andriansyah, A. (2016). From Gontor to Sorong: Muslim Minority Practices on Arabic Teaching and Learning. SOSIOHUMANIKA, 9(1).

Wekke, I. S., \& Astuti, R. W. (2017). Kurikulum 2013 di Madrasah Ibtidaiyah: Implementasi di Wilayah Minoritas Muslim. Tadris: Jurnal Keguruan dan Ilmu Tarbiyah, 2(1), 34.

Wekke, I. S., Hermawanto, A., \& Ashrori, M. (2016). Keberagamaan Mahasiswa Di Perguruan Tinggi Wilayah Minoritas Muslim. Ulul Albab, 17(2), 135.

Yusuf, H., Wekke, I. S., \& Yudha, G. (2018). Modern Science and Cosmology (The Implications of the Society's View of God). Opción, 34(16), 937-956.

Yusuf, M., \& Wekke, I. S. (2015). Active learning on teaching Arabic for special purpose in Indonesian Pesantren. Procedia-Social and Behavioral Sciences, 191, 137-141.

Yusuf, M., Nahdhiyah, N., \& Wekke, I. S. (2019). Dimension of Human Perfection Based on the Quran. Opción, 35(89), 402-418.

Zayu, W. P., \& Vitri, G. (2019). Permodelan Parkir Pasar Kota Padang Panjang. Jurnal Teknik Sipil ITP, 6(2), 88-97. 